\title{
Essay \\ Of Mirrors and Bell Jars. Heterotopia and Liminal Spaces as Reconfigurations of Female Identity in Sylvia Plath
}

\author{
Carmen Bonasera \\ Department of Philology, Literature and Linguistics, University of Pisa, via Santa Maria, 67, 56126 Pisa (PI), Italy; \\ carmen.bonasera@fileli.unipi.it
}

Received: 26 November 2018; Accepted: 22 January 2019; Published: 24 January 2019

\begin{abstract}
The poetry of Sylvia Plath (1932-1963) has received a considerable number of critical responses, among which spatial analysis occupies a minor position, although her texts explore complex relationships between subject and context. Drawing from a threefold theoretical apparatus (Bachelard's theory of the poetic space, the Foucauldian concept of heterotopia, and the trope of liminality), this article focuses on the analysis of Plath's increasing use of in-between spaces and objects of transition and transformations (mirrors, thresholds, windows), as well as on her predilection for heterotopic and alienating sceneries (hospital rooms, cemeteries), in both her poetry and prose. The study first acknowledges Plath's choice of spatial imagery as a progressive orientation towards transitional states and places of otherness and ambivalence. Then, it highlights the specific role of heterotopic and liminal spaces in the process of reconfiguration of female identity. Given the impossibility for the female subject to rely on imprisoning domestic spheres to suture the edges of her fragmented self, reconceptualization of her own consciousness only becomes possible in the movement across a threshold. The analysis finally determines that the poetic evocation of spaces of conflict and difference paradoxically contributes to the shaping of female identity.
\end{abstract}

Keywords: Sylvia Plath; poetic space; heterotopia; liminal spaces; female identity

\section{Introduction: Critical Perspectives on Sylvia Plath}

Since her death in 1963, the work of American poet Sylvia Plath (Boston, 1932-London, 1963) has been subject to a considerable number of critical interpretations: biographies, feminist studies, psychoanalytic investigations, stylistic and thematic criticism, and so on. ${ }^{1}$ Despite having published in her lifetime only one collection of poems, The Colossus (1960), and one novel, The Bell Jar (1963), the posthumous publication and critical acclaim of the poems in Ariel (1965) and of her letters and journals have established Plath among the most influential writers of her age. Several aspects of the spatial dimension in her poetry have already been discussed: significant critical works focus mainly on the relevance of domestic settings from a feminist perspective (Dobbs 1977; Bryant 2002; Bayley 2009), on the creation of psychological landscapes out of natural sceneries (Lindberg-Seyersted 1990), or on the reflections between natural backgrounds and poetic self (Rosenblatt 1979). Nevertheless, a systematic analysis of the symbology of space in Plath's production has yet to be produced, and the present contribution is a preliminary step in this direction. Indeed, in Sylvia Plath's poetry and prose, the analysis of the relevance of spatial paradigms, both referential and symbolic, is closely related to

1 For recent and comprehensive studies on Sylvia Plath's work, see (Rose 1992; Van Dyne 1994; Britzolakis 1999; Brain 2001; Gill 2006; Kroll 2007; Bayley and Brain 2011). 
the investigation of gender issues. Feminist theorists (Connell 1987; Massey 1994; McDowell 1999; Shands 1999) have used the relationship between female subjects and space to depict the symbolic interplay of contrasting gender powers; however, the outcomes of the theoretical speculation on female space have never been applied to the examination of Sylvia Plath's oeuvre. This essay intends to fill this void and to show that Plath's wide use of spatial metaphors could be interpreted moving further from gendered perspectives. The following paragraphs, in fact, argue that her vision of space can be read according to three different critical notions: firstly, Bachelard's theory of the poetic space; secondly, the Foucauldian concept of heterotopia; and thirdly, the literary trope of liminality. Delving into the spatial imagery of Plath's poetry and prose, while integrating geocritical theories with feminist approaches, this study aims at proving that heterotopic and liminal spaces play a significant role in the process of building modern female poetic identity. In order to provide an accurate theoretical background, the following paragraph offers a concise overview of the main theories of space that appeared in the 20th century, which will later shape the progression of the textual analysis.

\section{Space, Heterotopia, and Liminality in Theory and Practice}

In the last decades of the 20th century, the concept of spatiality progressively gained significance among literary criticism and cultural studies; postmodern and postcolonial paradigms contributed to such relevance, effacing traditional philosophical and geographical boundaries and outlining new ones. This renewed interest in spatiality is defined as 'spatial turn'; Tally (2012) provides a clear examination of this critical trend:

Although it would be difficult, and misleading, to identify a particular date or moment when this occurred, a recognizable spatial turn in literary and cultural studies [ ... ] has taken place. One cannot help noticing an increasingly spatial or geographical vocabulary in critical texts, with various forms of mapping or cartography being used to survey literary terrains, to plot narrative trajectories, to locate and explore sites, and to project imaginary coordinates. A great many literary studies and academic conferences have been devoted to matters of space, place, and mapping, and the spatial or geographical bases of cultural productions have, in recent years, received renewed and forceful critical attention. (ibid., pp. 11-12)

Given its intersection with cultural studies and with the ever-changing vision of contemporary reality, the so-called geocriticism or 'spatial critical theory' is characterized as a set of mutually-defining approaches (philosophical and political, as well as aesthetic) that aim at a better and broader understanding of the spatial relations that inform the postmodern world, allowing for the uncovering of previously-ignored relations of power (ibid., pp. 113-14). Although the first acknowledged impulse to the 'spatial turn' in critical theory was given by Michel Foucault in his 1967 lecture titled Des Espaces Autres, which is discussed later, the progenitor of this theoretical approach was French philosopher Gaston Bachelard. In The Poetics of Space (Bachelard [1958] 1994), Bachelard examines domestic spaces experienced by the poet from an epistemological perspective. His understanding of spatiality refers mainly to an inner space linked to poetic imagination: according to this view, real objects and places are relevant only in relation to the individual's affective response to them, i.e., how the subject interacts and inhabits spaces and the imaginative effects produced in the psyche. This view was then integrated by French Marxist philosopher Henri Lefebvre: in The Production of Space (Lefebvre [1974] 1991), he envisages a dialectic between abstract and social spheres, considering space not as a fixed reality, but as a social product of human practices and of a variety of processes. This theory was highly influenced by Foucault's conception of space and its relationship with power. In his 1967 lecture, which was only published in 1984, Foucault states that the 20th century established itself as the "epoch of space" (Foucault [1984] 1998, p. 175), causing many thinkers to consider the notion of space as a crucial entity in aesthetic, cultural, and philosophical discourse; this stands in contrast with the previous century, which focused mainly on temporality (both chronological and affective). Similarly to Lefebvre, he recognizes the performative and productive nature of space, focusing on power relations as they 
occur in a social context. He acknowledges Bachelard's phenomenology of domestic and interior spaces, but he also commits to explore the dialectic between domestic and exterior spaces ( $d u$ dehors), in which social forces move and assert themselves:

[W]e do not live in a kind of void, within which individuals and things might be located. We do not live in a void that would be tinged with shimmering colors, we live inside an ensemble of relations that define emplacements that are irreducible to each other and absolutely nonsuperposable. (ibid., p. 178)

Among different locations, Foucault is especially interested in exploring sites that maintain problematic and contradictory relationships with other spaces "that have the curious property of being connected to all the other emplacements, but in such a way that they suspend, neutralize, or reverse the set of relations that are designated, reflected, or represented by them" (ibid.). He classifies those spaces into two types: the first model is utopia, i.e., locations that, despite their analogy to real spaces, present society in an unreal form, alternatively as a sublime or corrupt agency. The second model, which will be the object of this study, is heterotopia. Foucault defines heterotopias as:

real places, actual places, places that are designed into the very institution of society, which are sorts of actually realized utopias in which the real emplacements, all the other real emplacements that can be found within the culture are, at the same time, represented, contested, and reversed, sorts of places that are outside all places, although they are actually localizable. (ibid.)

He then offers a systematic description of heterotopias. They can be places reserved for individuals whose behavior deviates from social norms (retirement homes, psychiatric asylums, hospitals, prisons, brothels, but also imprisoning domestic settings), as well as spaces that fulfill a precise function in society but are removed from collective imagination on the account of irrational fears (cemeteries), and finally, locations whose function alters time (such as museums, libraries or alternatively fairgrounds and vacation villages) or juxtaposes several incompatible sites (cinema, theatre). In Foucault's opinion, mirrors are the objects that best exemplify the intersection between utopia and heterotopia, in being "a placeless place" (ibid., p. 179). The mirror surface is a utopia in the sense that it opens up a virtual space, enabling the subjects to see themselves where they are, in fact, absent; it is a heterotopia as well, since it does exist in reality and its reflection allows subjects to feel real and connected to its surroundings, but it also causes a feeling of illusion and unreality, because subjects must acknowledge its virtual nature in order to perceive themselves.

More recent theories on space are closely associated with the themes of identity, ${ }^{2}$ while a large portion of feminist criticism has been concerned with spatial imagery and its relation to female body and power discourses. In this regard, feminism has focused on the shifting of women's condition on the grounds of a newer attention to spaces, boundaries and movements across thresholds and out of confinements. Throughout the 19th century and in the first half of the 20th, early feminists began to theoretically deconstruct traditional conceptualizations of space, aiming to expand women's horizons. Their discourse on space was influenced by Virginia Woolf's image of the room of one's own (Woolf [1929] 2015), a concrete place that stands for the need of a place for women writers within a traditionally male literary canon, in order to build a history of female writing. The third feminist wave (1980s-1990s) renewed its interest towards spatial metaphors, focusing instead on complex spaces and fluid transitions: their imagery is filled with movable borders, thresholds, open spaces, liquid and bodily symbols, refusing traditional dichotomies. ${ }^{3}$ For example, human geographer Massey (1994)

2 For instance, Martin and Miller (2003), following the example of Lefebvre and Foucault, consider space as socially produced, highly informing social practices and networks, while Smith (1999) sees places as a salient part of the construction of identity and of its markers of distinction.

3 In fact, third-wave feminists were eager to challenge the second wave's essentialist definitions of femininity, which, for example, did not account for racial minorities; thus, they promoted the intersection between feminist and postcolonial 
claims that women's spatial confinement to domestic spheres informs the making (and unmaking) of their identity, while literary theorist Shands (1999) maintains that feminist critical practice aims at deconstructing boundaries to extend women's power and strives to subvert the concept of fixed space, in order to give rise to more fluid conceptions.

These theories raise questions of liminality while problematizing the porous space in-between social and individual categories and concepts. Liminal spaces are defined as boundary zones between two spatial areas or two segments of time. In anthropology, liminality relates to rites of passage and to intermediate and transitional moments between different conditions. According to French ethnologist Arnold Van Gennep (Van Gennep [1909] 1960) and to British anthropologist Victor Turner (Turner [1967] 1970), these rites develop through a transformation of subjects from a stable condition to a subsequent detachment from it and a passage towards another state in which they are finally stable again: in-between this passage, subjects undergo a liminal period of uncertainty and displacement, in which they have lost all attributes of the previous state but have yet to gain new ones from the next stage. Hence, concepts of liminality and heterotopia are clearly intertwined, since liminality entails ambiguity and otherness, while heterotopia is by definition the place of otherness. In addition, liminality also reveals a spatial conception, given its etymology deriving from the Latin word 'limen' ('threshold'). Being constructed as a transitional state and space ("betwixt and between", Turner [1967] 1970, p. 97), liminality is thus symbolically reflected in thresholds, edges, mirrors, windows, walls, doors, and liquids. ${ }^{4}$

The question of liminality, shifting boundaries and negotiating spaces, is evidently related to gender discourses. Recently, feminist and gender thought has shifted away from binary formulations and from the separation of private and public spheres of influence, focusing more on the complex and permeable structures (in-)between spaces. As Gómez Reus and Gifford (2013, p. 2) point out, "[t]he need to examine the social and cultural implications of the 'separate spheres' paradigm, which was the focus of so much feminist scholarship in the second half of the twentieth century, has been gradually replaced by a new critical discourse that speaks of ambiguity, thresholds and porosity". Literary scholars have been progressively interested in exploring conditions and locations that blur and challenge the equation public/male and private/female, thus sharing Lefebvre's critical notion of space as a social, dynamic, and interconnecting product. Through the conceptualization of liminality, spaces help to constitute new and subversive configurations of identity: especially for women writers, literature itself may be understood as "a cultural space of liminality" (ibid., p. 6), since it occupies an intermediate and porous space between biographical reality and fictional representation, as well as between the phallocentric literary canon and their own voice. Moreover, since female subjects cannot rely any longer on the protective dimension of domestic settings, as its limitations have become unbearable to 20th century women, reconfiguration of their own identity is only possible through a movement across a threshold, be it physical, historical, or metaphorical. This need for reconfiguration was specifically experienced by female authors who wrote within the contradictory Cold War cultural frame. As several scholars (May 1988; Nelson 2002, inter alia) have exhaustively shown, American Cold War rhetoric laid its foundation on the security and privacy of the domestic sphere, comforted by postwar economic growth and by the rise of suburbs, whereas the government's paranoia towards the Communist threat fostered an atmosphere of surveillance, suspect, and defensive

discourse or racial concerns. A valuable example is the work of Chicana theorist Anzaldúa (1987) or of American philosopher Judith Butler, who challenged unproblematic binary dialectics (Butler [1990] 2006). Additionally, Gilbert and Gubar proposed to avoid dichotomies, claiming that male literature improperly categorized women as either monsters or angels (Gilbert and Gubar [1979] 2000).

4 The notion of liminality is also crucial to Postcolonial discourse, where it relates to the interconnections between colonizers and colonized: Bhabha (1994) claims that postcolonial cultural systems are constructed in liminal or 'in-between' spaces, and that cultural hybridity is then caused by a displacement that emerges from cultural encounters: it takes place in interstitial spaces within individuals and cultures (in-betweenness), which are part of an ongoing process that forms identities transcending Western binary beliefs. 
retreat. ${ }^{5}$ This ambiguity had peculiar consequences for American women artists and writers who generally challenged the patriarchal constriction of spaces; among these, Sylvia Plath shows a liminal stance. Writing between the 1950s and 1963, she both reclaimed and anticipated many feminist issues, but she "was deprived of the cultural, political and aesthetic framework in her own time that might have helped her to articulate these" (Gill 2008, p. 15). Therefore, her complex work epitomizes the deep interconnection of otherness and liminality with women's writing, providing both a representation of the female condition and a resolution to their sense of contradiction and fragmentation, which was due to an inherently ambiguous sociohistorical context.

\section{Spaces in Sylvia Plath: A Thematic Analysis}

Sylvia Plath's oeuvre is deeply rooted in spatial dimensions that include metaphorical geographies as well as references to real places that she visited or inhabited. Even a preliminary glance at the titles of her poems reveals the impact of actual locations on her creative process, meaning that she absorbed various places that inspired her and reconfigured them in her writing. The reader is invited into houses, shops, hospital rooms, city streets, kitchens, and open and undefined natural landscapes that come together to constitute a variety of spaces as diverse as the personae that she employs in her poems. While her discourse of space clearly involves issues of identity and social power, her focus is no longer on the classic feminist request for a room of her own, but on a more expanded concept of space, negotiating a place of her own outside of traditional delimitations. Spaces and places draw a peculiar geography throughout her entire work, resisting categories and limitations while expanding towards transitional states and places of difference that mirror the difficult conceptualization of female identity. The following sections assess Plath's choice of settings, on the premise of the array of theoretical approaches previously mentioned. These paragraphs provide a preliminary analysis of a selection of her poems, focusing especially on those written approximately between 1961 and 1962, around her major creative burst, as well as of some excerpts of her novel The Bell Jar. More specifically, poetic texts have been chosen essentially on a thematic basis, according to their relevance to this essay's purpose, which is to account for the development in Plath's depiction of spaces by drawing a symbolic and intertextual trajectory in her work: from domestic settings to heterotopic milieus, until the mature shift towards liminal images and transitional landscapes.

\subsection{Impossibility of Topophilia in Domestic Settings}

Bachelard's notion of topophilia ${ }^{6}$ is helpful in delineating the impact of inhabited spaces on the poet's psyche, providing a description of the ways in which the experience of place reflects on its poetic representation. Bachelard claims that topophilia resides mainly in 'felicitous spaces' such as one's own house, i.e., "the sorts of space that may be grasped, that may be defended against adverse forces, the space we love" (Bachelard [1958] 1994, p. xxxv). This view is confirmed by Shands (1999, p. 8), who claims that women writers usually connote home positively, as safe places against the outside world. Places that have a positive impact on inner life, however, offer an incomplete conception of space, since they fail to consider conflict, dissonance, and ambiguity. While Bachelard's theory of topophilia avoids accounting for unpleasant heterotopias and spaces of ambivalence ("space of hatred and combat can only be studied in the context of impassioned subject matter and apocalyptic images" (Bachelard [1958] 1994, p. xxxvi)), Plath's writing seems particularly eager to unravel such spaces. In her work, positive spaces are generally absent, since the locations she describes are often shadowed by anxiety and ambiguity, far from being comforting and pleasant. Indoor domestic settings in her poetry are always sinister and ambivalent, mirroring her concerns towards female agency: the speaker usually represents

5 For exhaustive investigations on Cold War rhetoric and culture, see also (Hinds and Windt 1991; Nadel 1995; Medhurst and Brands 2000; Piette 2009).

6 Later developed by human geographer Yi-Fu Tuan (Tuan [1974] 1990). 
houses, kitchens, and rooms as pervaded by a sense of imprisonment or impending doom. This finds an explanation by looking at the social and cultural context in which Plath lived and worked. The Cold War cultural milieu challenged the boundaries between private and public realities, contributing, for instance, to the emergence of a poetic style based on personal disclosure (the Confessional poetics to which Plath was related), while also regarding such disclosure with suspicion and aversion (Nelson 2002, p. 77). Moreover, the return of soldiers after the war and the increase in population contributed to the vertiginous rise of suburbs, where families began to move on the grounds of cheaper rates and the ultimate possibility of owning their own house. In brief, American families "subscribed to an ascendant domestic ideology that revised traditional familial values for the Cold War era" (Rotskoff 2002, p. 7). For women, this idealized domestic rhetoric was as comforting as it was oppressing: in The Feminine Mystique, Betty Friedan illustrates how middle-class women were urged to marry at a very young age and to direct their ambitions on their family and on domestic chores, without seeking any personal fulfillment outside (Friedan [1963] 1983). While these conditions eventually helped to shape a new feminist movement, writers like Plath clashed with such demanding pressures and, inevitably, mirrored them in their work, primarily through the subjective depiction of domestic settings. ${ }^{7}$ Friedan also significantly focuses on the role of media, such as women's magazines and advertisements. She explains that the cultural atmosphere set forth by advertisements targeted housewives, proposing female confinement in the kitchen and their exclusion from the typically masculine outside world, thus utterly disempowering them. Advertising plays a central role also in shaping Plath's construction of domesticity. As Bryant (2002, p. 21) points out, the speaker in Plath's poems is deeply influenced by the surreal rhetoric of magazines and television ads, mixing "the magical properties and hyperbolic situations of advertising with her own brand of kitchen craziness", and fusing, as Perloff (1985, p. 283) suggests, "the domestic and the hallucinatory". Therefore, Plath's characterization of domestic spaces often borders the realm of the uncanny, moving ambiguously between representation and fictionality. In 'Lesbos' (1962), the kitchen becomes the setting of a deceitful relationship between two housewives. The reference to the island where the poet Sappho lived appears to posit the poem in a higher literary context, only to stand in painful contrast with the dull and claustrophobic kitchen milieu.

Viciousness in the kitchen!

The potatoes hiss.

It is all Hollywood, windowless,

The fluorescent light wincing on and off like a terrible migraine,

Coy paper strips for doors-

Stage curtains, a window's frizz,

And I, love, am a pathological liar (1-7, Plath 1981, p. 227)

The opening lines of this poem invite the reader into the intimate space of the kitchen, only to reveal a staged performance. The references to Hollywood, to stage curtains as doors, and to lies suggest that the domestic atmosphere is fictitious; here, women are performing a role dictated by society, rather than being authentic. This is confirmed by the description of the other woman, who appears to be a former actress that somehow abandoned her career to devote herself to her family: "Once you were beautiful./In New York, in Hollywood, the men said: 'Through?/Gee baby, you are rare.' /You acted, acted, acted for the thrill." (40-43, ibid., p. 228). This shows Plath's ability to mirror and transfigure the public rhetoric of Cold War paranoia and surveillance into her own poetic discourse; as Bayley (2009, p. 550) claims, "[t]he relocation of a very public rhetoric into the most private of arenas produces a deliberately inauthentic performance of the private, a carefully staged

7 The relationship between Plath's writing and Cold War discourses has been studied extensively. See (Dobbs 1977; Peel 2002; Nelson 2006; Bayley 2006; Britzolakis 2013). 
undoing of its sacred precincts, a forced confession of wrongdoing at home". Although the poem mainly takes place in the kitchen, the speaker mentally explores other spaces, albeit only as a reverie: "I should sit on a rock off Cornwall and comb my hair./I should wear tiger pants, I should have an affair./We should meet in another life, we should meet in air,/Me and you." (29-32, Plath 1981, p. 228). In these lines, the speaker muses about switching to another way of living, outside of the imprisoning kitchen, placing herself in an outdoor space. The rhyming of "hair", "affair", and "air" represents her wish for breaking free from the claustrophobic role imposed on women, as well as the impossibility of realizing such a wish, which seems to disappear into thin air.

The idea of the domestic setting as an ambivalent place is recurrent in other poems. Among those, 'The Detective' (1962) takes place in a house with very sinister qualities. As in 'Lesbos', the kitchen stands as a symbol for a deceitful and artificial familial state: "This is the smell of years burning, here in the kitchen,/These are the deceits, tacked up like family photographs" (12-13, ibid. p. 208). The inquiries of the detective voice emphasize the ambiguous setting, and the violent imagery that associates it with destruction suggests a tense dissolution of the space itself into an apocalyptic undefined landscape: "It is a case of vaporization [ . . . ] We walk on air, Watson./There is only the moon, embalmed in phosphorous./There is only a crow in a tree." (26, 38-40, ibid., p. 209). While controverting Bachelard's assumption that topophilia relates only to blissful places, this brief mention of two Plath poems alludes to the speaker's uneasy imprisonment in strange and disquieting milieus.

The conflict between social imposition and individual aspirations is also at the core of Plath's novel, The Bell Jar, which describes the breakdown and partial recovery of an American teenager in the 1950s, named Esther Greenwood. Frustrated by the need of defining herself, she is torn between the ambition of becoming a writer and the social imposition of marriage and family. ${ }^{8}$ Among the multiple causes of Esther's alienation, the typical Cold War social oppression and female domestic constraint is pivotal. For instance, her boyfriend tells her that "[w]hat a man wants is a mate and what a woman wants is infinite security" and "[w]hat a man is is an arrow into the future and what a woman is is the place the arrow shoots off from" (Plath [1963] 2005, p. 67), whereas she states that "[t]he last thing I wanted was infinite security and to be the place an arrow shoots off from. I wanted change and excitement and to shoot off in all directions myself, like the coloured arrows from a Fourth of July rocket" (ibid., p. 79). This might suggest a conventional feminist-oriented approach: the reader might focus on women's wish to escape from cultural and spatial limitations, represented through a tension between images of enclosure and symbols of "fluidity and boundarylessness" (Shands 1999, p. 72). While a feminist vision certainly contributes to the understanding of her texts, Plath's spatial dynamic presents a far deeper complexity, one that may not be dealt with exhaustively through a gendered perspective, nor through a single interpretation of the spatial dimension, as demonstrated in the following paragraphs.

\subsection{Pervasiveness of Heterotopic Settings in Plath's Poetry and Prose}

The concept of the subject's imprisonment in a domestic setting evokes Foucault's theory of heterotopia, i.e., those places that exist in society and relate to other surrounding places but act as counter-sites in which other real sites are simultaneously represented and inverted. Heterotopia mainly takes place in moments of crisis: as Foucault claims, "there are privileged or sacred or forbidden places reserved for individuals who are in a state of crisis with respect to society and the human milieu in

8 Particularly interesting is the metaphor of the fig tree, through which Esther describes her inability to choose between mutually exclusive perspectives of life and career: "I saw my life branching out before me like the green fig-tree in the story. From the tip of every branch, like a fat purple fig, a wonderful future beckoned and winked. One fig was a husband and a happy home and children, and another fig was a famous poet and another fig was a brilliant professor, and another fig was Ee Gee, the amazing editor [ . . . ]. I saw myself sitting in the crotch of this fig-tree, starving to death, just because I couldn't make up my mind which of the figs I would choose. I wanted each and every one of them, but choosing one meant losing all the rest, and, as I sat there, unable to decide, the figs began to wrinkle and go black, and, one by one, they plopped to the ground at my feet." (Plath [1963] 2005, p. 73). 
which they live" (Foucault [1984] 1998, p. 179). This kind of heterotopic setting is represented by places of deviation that host individuals whose behavior deviates from the required social norms. In this sense, typical instances are rest homes, psychiatric hospitals, and prisons where deviant subjects are placed. In The Bell Jar, Esther is characterized as a deviant subject; although at first she struggles to conform to the elegant urban world in which she has been placed, she grows apathetic and alienated from her own aspirations, finally detaching from the mainstream lifestyle she was pursuing. This causes a deviation from the normal individual functioning, and ultimately leads to her mental breakdown and suicide attempt. As a result, she is later confined in a mental institution and undergoes electroconvulsive therapy; the space of the asylum is described as deeply ambivalent, since it may be read either as a heterotopic prison or a liminal phase in the rite of passage towards sanity.

By extension, even the constraining domestic milieu found in her poetry may fit the description of heterotopia. For example, 'Apprehensions' (1962) describes the four different walls of a non-specified room. The description of the walls that enclose the subject is then juxtaposed with the roaming into her perception and mind, which ultimately becomes another place of imprisonment ("Is there no way out of the mind?", 7, Plath 1981, p. 195). Furthermore, concepts of imprisonment seem pervasive in Plath's poetry: 'In Plaster' (1961) is a poem in which the subject's consciousness directly confronts its own enclosure. It was written during a period in which Plath was hospitalized for an appendectomy, where she shared a room with a patient in full-body plaster, as Hughes explains in the notes to the poem (ibid., p. 291). The text depicts a situation of a split self, mirroring the plot of The Bell Jar, which Plath was in fact writing at that time. The body cast, which the speaker calls "[ $\mathrm{t}] \mathrm{his}$ new absolutely white person" (2, ibid., p. 158), "certainly the superior one" (3, ibid.), becomes the better and tidier version of herself, while its broken and weak inhabitant symbolizes her socially inadequate self, who in the novel ends up confined in the asylum.

I shall never get out of this! There are two of me now:

This new absolutely white person and the old yellow one,

And the white person is certainly the superior one.

She doesn't need food, she is one of the real saints.

At the beginning I hated her, she had no personality-

She lay in bed with me like a dead body

And I was scared, because she was shaped just the way I was

Only much whiter and unbreakable and with no complaints.

I couldn't sleep for a week, she was so cold.

I blamed her for everything, but she didn't answer.

I couldn't understand her stupid behavior!

When I hit her she held still, like a true pacifist.

Then I realized what she wanted was for me to love her:

She began to warm up, and I saw her advantages. (1-14, ibid., pp. 158-59)

This condition of imprisonment is related to the social implications of married life in the 'domestic' poetry previously presented. While the speaker begins to gradually adjust to life in plaster ("I gave her a soul, I bloomed out of her as a rose/Blooms out of a vase of not very valuable porcelain", 16-17, ibid., p. 159), she also hints at her dissatisfaction, wishing to break free from the cast. Whereas the plaster self, with "her tidiness and her calmness and her patience" $(25, \mathrm{ibid}$.$) , presents ideal wifely qualities,$ the inner self begins to realize how the smothering relationship with the outer self has weakened her ("And my skin itched and flaked away in soft pieces", 33; "I wasn't in any position to get rid of her./She'd supported me for so long I was quite limp-/I had even forgotten how to walk or sit", 43-45; "Living with her was like living with my own coffin/Yet I still depended on her, though I did it regretfully." 48-49, ibid., pp. 159-60). The imprisoning pattern is thus portrayed as a sort of mutual dependence that represents a necessary cure for the self, but it also turns out to be toxic and destructive. The space of the imprisoning plaster, as well as the space of the asylum or the hospital, is accurately 
defined as heterotopic: in being enclosed in a cast, the subject is found both in a moment of crisis and deviation from physical health, so she is removed from conventional spaces and confined in another place; this other place, however, remains connected with the outside world and with people ("it was I who attracted everybody's attention", 18, ibid., p. 159), and this is emphasized by the speaker's wish to "avenge" (47, ibid., p. 160) herself and to reprise her functional role in society ("I'm collecting my strength; one day I shall manage without her/And she'll perish with emptiness then, and begin to miss me", 55-56, ibid.). This ambivalent posture of the self is found also in 'The Jailer' (1962), in which the speaker is a female victim to a male oppressor, who is, however, depending on her presence as the victim: "What would the dark/Do without fevers to eat?/What would the light/Do without eyes to knife, what would he/Do, do, do without me?" (41-45, ibid., p. 227).

Barren and artificial hospital rooms are the set of many other Plath poems, as in 'The Surgeon at 2 a.m.' (1961), where she describes the hospital room: "The white light is artificial, and hygienic as heaven" (1, ibid., p. 170), or 'Tulips' (1961). Like 'In Plaster', 'Tulips' is set in a hospital room where the chromatic dichotomy between the white room and the defiant red flowers symbolizes the inner conflict between wanting to die and being forced to survive. The poem shows the speaker taking pleasure in surrendering to quiet and numbness, in a sort of self-effacement that resembles death. This condition of peacefulness is compared to freedom:

I didn't want any flowers, I only wanted

To lie with my hands turned up and be utterly empty.

How free it is, you have no idea how free-

The peacefulness is so big it dazes you,

And it asks nothing, a name tag, a few trinkets.

It is what the dead close on, finally; I imagine them

Shutting their mouths on it, like a Communion tablet. (29-35, ibid., p. 161)

Ultimately, the vitality of the red tulips manages to remind the speaker that her death is only an illusion, and to bring her back to life, albeit passive and reluctant ("And I am aware of my heart: it opens and closes/Its bowl of red blooms out of sheer love of me", 60-61, ibid., p. 162). Nevertheless, the poem's hospital room acts as another evidence of the employment of heterotopic settings in poetry. In addition, referring to the room's "big" peacefulness (32), the poem combines a dimensional element with the semantic domain of consumption and death ("what the dead close on", 34), thus linking the situation to another heterotopic setting: the graveyard. Foucault argues that the cemetery is a peculiar cultural space, one which "is connected to all the other emplacements of the city or the society or the village, since every individual, every family happens to have relatives in the cemetery" (Foucault [1984] 1998, p. 180). Nevertheless, since the 19th century, when graveyards were built outside of the city center, the space of the cemetery gained an aura of otherness, despite its connection to ordinary human life. Unsurprisingly, the sterile landscape of the graveyard attracted Plath, namely in 'November Graveyard' (1956), 'The Moon and the Yew Tree' (1961), also set in a churchyard, and in 'The Munich Mannequins' (1963), whose reference to yew trees helps to depict a desolate graveyard scenery.

\subsection{Through the Looking Glass: The Symbolism of Mirrors}

In Foucault's view, the mirror is the ordinary object that best represents the concept of heterotopia. As previously noted, he argues that mirrors are ambivalent objects. Their surface proposes a virtual space which reflects and duplicates the scene and the subject. While allowing individuals to see themselves as connected to their surroundings, mirrors instill a sense of uneasiness, since subjects always perceive themselves as fragmented and refracted between their position and their gaze (Foucault [1984] 1998, p. 179). In literature and poetry, the mirror surface has always been crucial to the representation of the doubling of the self, on the grounds that mirrors epitomize the divergence between self-perception and the image of the self that is reproduced by the text. French philosopher Jacques Lacan wrote extensively on mirror symbolism, showing how the image reflected by mirrors 
allows the individual to configure a unitary identity, although his self-perception gives the effect of a fragmented body (Lacan [1966] 2006, p. 97). The opinion that Plath's poetry is deeply concerned with images of fragmentation has been shared by several scholars (Axelrod 1985; Van Dyne 1994; Boileau 2017), as has the belief that fragmentary and disconnected experiences may lie behind an apparently unitary identity. In addition to Plath's poetic work, images of multiple selves recur in The Bell Jar, where the metaphorical disintegration of the self is portrayed twice after Esther's suicide attempt, and always through images of reflection. Firstly, shocked by her own appearance, she accidentally breaks a mirror in the hospital:

The most startling thing about the face was its supernatural conglomeration of bright colours.

I smiled.

The mouth in the mirror cracked into a grin.

A minute after the crash another nurse ran in. She took one look at the broken mirror, and at me [...]. (Plath [1963] 2005, p. 168)

and secondly, disintegration relates to the splitting of little reflective mercury balls from a tray of thermometers that she knocked over the edge of her bed: "I poked my head out of the covers and stared over the edge of the bed. Around the overturned enamel tray, a star of thermometer shards glittered, and balls of mercury trembled like celestial dew" (ibid., p. 176).

As for Plath's poetic trajectory, one may safely say that 'Mirror' (1961) stands as a turning point in her spatial imagination; even a general reading of the text suggests the deep intertwining between the theoretical concept of heterotopia, the critical discourse on female identity, and the relevance of the notion of liminality for her poetic development.

I am silver and exact. I have no preconceptions.

Whatever I see I swallow immediately

Just as it is, unmisted by love or dislike.

I am not cruel, only truthful,

The eye of a little god, four-cornered.

Most of the time I meditate on the opposite wall.

It is pink, with speckles. I have looked at it so long

I think it is part of my heart. But it flickers.

Faces and darkness separate us over and over.

Now I am a lake. A woman bends over me,

Searching my reaches for what she really is.

Then she turns to those liars, the candles or the moon.

I see her back, and reflect it faithfully.

She rewards me with tears and an agitation of hands.

I am important to her. She comes and goes.

Each morning it is her face that replaces the darkness.

In me she has drowned a young girl, and in me an old woman

Rises toward her day after day, like a terrible fish. (Plath 1981, pp. 173-74)

This text is construed on the rhetorical leitmotiv of personification, since the speaker is immediately qualified as a mirror. The poem relies on a catoptric structure, in which two symmetric stanzas of the same length reflect and refract each other. While the first stanza focuses on the mirror's ability to faithfully reproduce an image, the second stanza conveys a transition, since the mirror becomes a liquid space ("Now I am a lake", 10). Here, an upset woman bends on the surface to look at her reflection, maybe hoping for a flattering image. The poem thus demystifies the reference to the myth of Narcissus, since the woman is upset and shocked by the signs of her old age, rather than by her beauty. The surface of the lake conveys a disturbing portrait of the woman, revealing that her 
appearance is no longer young nor beautiful. The young girl she once was drowned in the lake, and the monstrous image that emerges is the only truthful reflection she might find. In this sense, the mirroring surface acts as a heterotopic space, since it exists in space, but its stance is functional to a deviation to the norm: while it may reproduce a unitary image, it actually conveys a fragmented and deeply disturbed consciousness.

The complex symbolism of mirrors is recurrent in Plath's poetry. For instance, in 'In Midas' Country' (1958), the static reflection of the surface of a river is shattered by the intrusion of water skiers and "quivers to smithereens" (19, ibid. p. 100), while in 'The Couriers' (1962), mirrors cause a disruption of quietness, later embraced by the speaker: "A disturbance in mirrors/The sea shattering its grey one/Love, love, my season" (11-13, ibid., p. 247). In other poems, the mirror suggests a state of calm ('Brasilia', 1962), of wisdom and knowledge ('Totem', 1963), the conflicting desires of maternity ('Morning song', 1961) and of death ('A Birthday Present', 1962). Overall, the mirror symbolism suggests Plath's concern with the projection of a divided self, a recurrent image that has been already introduced in 'In Plaster'. The oscillation between inner and outer self, or between the true self and the version imposed upon by society, is metaphorically associated to the conflict between the desire for self-destruction and the transcendence of consciousness. This complex alternation between self-assertion and self-destruction is aesthetically transfigured in protean images of escape, transformation, and rebirth, which are subsequently transposed in spaces of liminality. Mirrors, thresholds, windows, walls, and other kinds of blurred boundaries represent the spatial equivalent of the subject's transition between conflicting versions of the self, as well as between contrasting domains of reality and illusion, or of death and rebirth.

\subsection{Thresholds, Transformative Spaces, and Liminal Imagery}

The anthropological and philosophical issue of liminality is crucial to the final phase of Plath's career, since thresholds, in-between spaces, and transformative images permeate her poems and novel. The very format of The Bell Jar, in fact, resembles liminality, being characterized as a Bildungsroman: it focuses on Esther's confrontation with social impositions and on her difficult transition from youthful subjection to adult independence, as well as on her struggle between public and private self. As a matter of fact, thresholds are best exemplified by the image of the window. The frequent use of window imagery in relation to domesticity and to the female condition is shown in 'Lesbos', where Plath depicts the American suburban lifestyle as "all Hollywood, windowless" (3, ibid., p. 227), in "The Munich Mannequins" (1963), where she curses the "domesticity of these windows" (21, ibid., p. 263), damning the domestic burden imposed on women, or in "Gigolo" (1963), where she describes the suburban landscape as "a palace of velvet/with windows of mirrors" (5-6, ibid., p. 267). The use of the domestic trope of the window suggests the complex negotiation between public and private spheres, as well as the social anxiety related to Cold War culture. In addition, Plath's use of window imagery is significant to the mutual connection between gendered and spatial discourse, since she manifests how, through domestic windows and walls, women are at once imprisoned and free, safe and in danger. The projection of this complex spatial relation through the window, which is located at the crossroads between heterotopia and liminality, aims at mirroring the multifaceted conflict between private and public, as well as at blurring the boundaries of such a distinction. The symbol of the bell jar bears analogies to the window: a bell jar is a bell-shaped glass laboratory instrument, made to preserve specimens or gas. In the novel, this image symbolizes Esther's entrapment in her mental condition and in the physical space of the asylum: she sees herself subdued and preserved against her will, "stewing" in her own "sour air" (Plath [1963] 2005, p. 178). The glass bell jar, however, is also a window from which the hallucinated subject observes the world, since "[t]o the person in the bell jar, blank and stopped as a dead baby, the world itself is the bad dream" (ibid., p. 227).

As for transformative spaces in poetry, it is no wonder that many of the so-called 'transitional poems' posthumously included in Crossing the Water (1971), whose title instantly suggests transition, share themes of rebirth, transformation, and reflection. Unsurprisingly, among these poems, one 
can find 'In Plaster' and 'Mirror', which are essentially interwoven with the theme of identity, as the previous reading has shown. Similarly, 'Face Lift' (1961) portrays a subject who tries to reverse her aging process by undergoing a face lift, thus acknowledging her conflicted identity and taking charge of her physical transformation. Here, the attempt at regeneration reflects the transitional process in rites of passage: the subject must detach herself from a previous stage and pass through an ambiguous liminal phase in which she has lost all attributes of the previous condition but has yet to gain new ones from the future state. In fact, forced by social pressures to reconcile different versions of herself, the speaker disassociates from her body ("Darkness wipes me out like chalk on a blackboard", 15; "Skin doesn't have roots, it peels away easy as paper", 20) in order to be reborn again, "mother to myself, I wake swaddled in gauze/pink and smooth as a baby" (31-32, Plath 1981, p. 156). The liminal space between death and resurrection can be thus described in animal terms, as a snake-like peeling of her skin or a coming out of a cocoon of gauze.

The same sense of transcendence is displayed in a series of 'landscape poems'. 'Parliament Hill Fields' (1961) portrays a tension between the desire to dissolve into the barren landscape and the opposite drive to keep one's own self-determination. The desolate landscape is described in gloomy terms: the speaker is presumed to watch the scene from a "bald hill" (1), the sky is depicted as "faceless and pale as china" (2), the city is said to be "melt[ing] like sugar" (12), whereas later, the hill is portrayed as a "tumulus" that "even at noon, guards its black shadow" (26, ibid., pp. 152-53). A similar desolated landscape is found in the first lines of 'Wuthering Heights' (1961), where the horizons "only dissolve and dissolve/Like a series of promises" (8-9, ibid., p. 167), and of 'Finisterre' (1961), "the land's end: the last fingers, knuckled and rheumatic,/Cramped on nothing" (1-2, ibid., p. 169). Landscapes are, thus, somehow filtered through the subject's emotional agitation: as Lindberg-Seyersted (1990, p. 510) suggests, "the poet creates 'psychic' landscapes out of concrete places, scenes and objects", hence establishing a connection between a barren scenery and a dreary mood. In 'Parliament Hill Fields', the speaker's sense of mourning is emphasized when she describes herself as "Ghost of a leaf, ghost of a bird/I circle the writhen trees" (28). ${ }^{9}$ This feeling of ephemeral existence, drifting through the wind like a leaf or a bird, is enhanced by the reference to death and afterlife, since she is in fact $a$ ghost of a leaf or a bird. This is then emphasized by the reference to "these faithful dark-boughed cypresses" (30), a grave from which, however, rebirth is possible through a return to "the old dregs, the old difficulties"(48) that bring her back to "the lit house" (50, ibid., p. 153).

By contrast, a later phase in Plath's production is characterized by poems like 'Ariel' and 'Lady Lazarus' (both 1962), in which transcendence reaches its completion. 'Lady Lazarus' mainly takes place in the mind of the speaker, who is caught in an exhibitionist bravado while she claims to be able to commit suicide and come back to life, much like a phoenix ("Out of the ash/I rise with my red hair/And I eat men like air", 82-84, ibid., p. 247). The analogy in the rhyming pattern between these lines and the ones in 'Lesbos' emphasizes the contrast between the two female conditions: ${ }^{10}$ in 'Lesbos', the housewife had no possibility of liberation, whereas in 'Lady Lazarus', rebirth is a viable, even cyclic opportunity ("One year in every ten/I manage it", 2-3, ibid., p. 244). There is a narrative connection between the retelling of suicides in 'Lady Lazarus' and the description of Esther's attempt. When she experiences her mental breakdown, she overdoses on sleeping pills and crawls into a narrow basement shelter, much like a return to the maternal womb; she is then retrieved after various days and she survives but is left with a scar on her face, as a mark of her encounter with death. Likewise, in 'Lady Lazarus' the speaker says:

9 In the Collected Poems edition, a note to 'Parliament Hill Fields' refers Plath's own explanation of the poem: “The speaker here is caught between the old and the new year, between the grief caused by the loss of a child (miscarriage) and the joy aroused by the knowledge of an older child safe at home. Gradually the first images of blankness and silence give way to images of convalescence and healing as the woman turns, a bit stiffly and with difficulty, from her sense of bereavement to the vital and demanding part of her world which still survives" (Plath 1981, p. 290-91).

10 "I should sit on a rock off Cornwall and comb my hair./I should wear tiger pants, I should have an affair./We should meet in another life, we should meet in air" (29-31, ibid., p. 228). 
The second time I meant

To last it out and not come back at all.

I rocked shut

As a seashell.

They had to call and call

And pick the worms off me like sticky pearls. (37-42, ibid., p. 245)

Finally, the landscape depicted in 'Ariel' is utterly indefinite and nebulous, dissolved in a kaleidoscopic multiplicity of fragments, substances, and colors, which are experienced by a speaker who is presumably riding a horse and losing control of it. Developing an intricate spectrum of analogies, the poem takes place before dawn ("Stasis in darkness/Then the substanceless blue", 1-2, ibid., p. 239) and ends just when the sun is rising ("Into the red eye/The cauldron of morning", 30-31, ibid., p. 240), which are, therefore, two liminal moments in the course of the day; as for the scenery, the speaker is only able to catch glimpses of her surroundings:

The furrow

Splits and passes, sister to

The brown arc

Of the neck I cannot catch,

Nigger-eye

Berries cast dark

Hooks-

Black sweet blood mouthfuls,

Shadows.

Something else

Hauls me through air- (6-16, ibid., p. 239)

Nevertheless, those momentary glances at the space are functional to the transcendence of the self, and to its transition from worried rider to an unleashed spirit that is able to become one with nature. She merges with her surroundings ("And now I/Foam to wheat, a glitter of seas", 22-23, ibid.), while distant sounds fuse together in the landscape ("The child's cry/Melts in the wall", 24-25, ibid.), and finally, she becomes one with the horse's race towards the sun, in a sort of ecstatic cosmic fusion:

And I

Am the arrow,

The dew that flies

Suicidal, at one with the drive

Into the red

Eye, the cauldron of morning. (26-31, ibid., pp. 239-40)

In the poem's final lines, her release and ultimate transcendence from her physical self is completed. The speaker of Plath's poems, presumably a woman, is no longer confined in the dull domestic milieu, or in the heterotopic space of the hospital. After crossing waters and thresholds, she has transcended liminality and has seized a new, more extended space for herself, ultimately blurring every boundary. Quite similarly, The Bell Jar ends on Esther's apparent rehabilitation from depression, as the bell jar begins to symbolically lift ("suspended, a few feet above my head", Plath [1963] 2005, p. 206) and to free her. As she recovers access to "the circulating air" (ibid.), 
the space that she inhabits seems more harmonious, and it is conveyed through images of open air, blue skies, sun, and birds. Nevertheless, she ignores whether "the bell jar, with its stifling distortions" (ibid., p. 230) would someday descend again, but indeed she feels confident while she steps across the threshold of the room where she will be evaluated for dismissal. She has completed her ritual of symbolic death and rebirth, a liminal rite of passage that she describes as "being born twice-patched, retreaded and approved for the road" (ibid., p. 233).

\section{Negotiating Female Spaces: Final Comments}

This condensed analysis has shown that Sylvia Plath's complex production of space is placed at the crossroads of different theoretical and conceptual domains. First, her interpretation of domestic settings relates to Bachelard's notion of poetic space, although her speaker, profoundly concerned with the oppressing Cold War rhetoric, perceives domesticity as a realm of anxiety and ambiguity from which the female self needs to escape. Second, the pervasiveness of heterotopic sceneries (such as asylums, imprisoning settings, walls, hospital rooms, and graveyards) submits her poetry to an explicit Foucauldian interpretation, while also conveying the problematic exploration of the concept. The subject's confrontation with peculiar heterotopic spaces (the mirror, for example) is always ambivalent, since they reflect her inner partition and her struggle to configure a unitary identity. Furthermore, mirror imagery has been considered a turning point in Plath's spatial discourse. The fragmentation of selves conveyed by mirrors directly relates to themes of transformation and leads to the final conceptual area of this study: liminality. In Plath, thresholds and in-between places become the spaces in which reconfiguration of female identity is possible, thus blurring the previous boundaries that had enclosed women in the domain of otherness. Undoubtedly, Plath's entire work is conspicuously complex and heterogeneous; therefore, this analysis may only represent the tip of the iceberg. Since this investigation only focused on a cautious selection of texts, an exhaustive interpretation of her relationship with spatial dimensions might only be reached with more extensive studies.

In any case, the essay has distinctly demonstrated that spatial images are deeply intertwined with the question of female identity. In her poetry and prose, Plath chooses to textualize the lack of a proper space for women and to react against patriarchal social codes that limited them to enclosed spaces. The fragmentation and loss of identity that emerge from being entrapped in heterotopic and confined settings are resolved with the transcendence across liminal spaces and phases. Furthermore, the blurring of divisions and the crossing of thresholds result in the progressive blurring of the boundary between self and other, death and rebirth, or even male and female identity. For instance, the speaker of 'Lesbos', the first poem that has been mentioned here, is clearly perceived as female, whereas on the opposite end, the speaker of 'Ariel' is an androgynous figure, a claim that is reinforced by the reference to the airy spirit Ariel from Shakespeare's Tempest.

In terms of the construction of spatial identity, enclosed and static spaces (such as kitchens, rooms, and walls) are commonly associated with femininity, in opposition to movement and dynamism being notably related to masculinity. In the final steps of her poetic career, Plath challenged such idealized stereotypes. Confronting delimitations and liberating expanded spaces, she denounced the sense of loss and displacement perceived by women and reclaimed her right to negotiate a place of her own, which eventually will correspond to the revival of a new, truer self. In this sense, the very act of writing becomes a space of transcendence, in that it explores the enclosures and the edges of consciousness and it strives towards a space of self-affirmation. Shifting (in-)between walls, mirrors, and bell jars, a new voice emerges: the resonating voice of the creative female artist.

Funding: This research received no external funding.

Acknowledgments: I am grateful to guest editors Eleonora Rao and Robert Tally for their interest in my topic. I also wish to acknowledge valuable feedback provided by the anonymous reviewer on an earlier version of this paper.

Conflicts of Interest: The author declares no conflict of interest. 


\section{References}

Anzaldúa, Gloria E. 1987. Borderlands/La Frontera. The New Mestiza. San Francisco: Aunt Lute Books.

Axelrod, Steven Gould. 1985. The Mirror and the Shadow: Plath's Poetics of Self-Doubt. Contemporary Literature 26: 286-301. [CrossRef]

Bachelard, Gaston. 1994. The Poetics of Space. Translated by M. Jolas. Boston: Beacon Press. Originally published as 1958. La Poétique de l'Espace. Paris: Presses Universitaires de France.

Bayley, Sally. 2006. 'I have your head on my wall': Sylvia Plath and the Rhetoric of Cold War America. European Journal of American Culture 25: 155-71. [CrossRef]

Bayley, Sally. 2009. 'Is it for this you widen your eye rings?' Looking, Overlooking and Cold War Paranoia: The art of the voyeur in the poetry of Sylvia Plath and the films of Alfred Hitchcock. Women's History Review 18: 547-58. [CrossRef]

Bayley, Sally, and Tracy Brain, eds. 2011. Representing Sylvia Plath. New York: Cambridge University Press.

Bhabha, Homi K. 1994. The Location of Culture. Abingdon: Routledge Classics.

Boileau, Nicolas Pierre. 2017. 'And I have no face, I have wanted to efface myself'. Sylvia Plath's Autothanatography or Death Writing. E-Rea 15. [CrossRef]

Brain, Tracy. 2001. The Other Sylvia Plath. Harlow: Pearson Education.

Britzolakis, Christina. 1999. Sylvia Plath and the Theatre of Mourning. Oxford \& New York: Clarendon Press.

Britzolakis, Christina. 2013. Dreamwork: Sylvia Plath's Cold War Modernism. Women: A Cultural Review 24: 263-73. [CrossRef]

Bryant, Marsha. 2002. Plath, Domesticity, and the Art of Advertising. College Literature 29: 17-34.

Butler, Judith. 2006. Gender Trouble. Feminism and the Subversion of Identity. London: Routledge. First published 1990.

Connell, Raewyn W. 1987. Gender and Power: Society, the Person and Sexual Politics. Stanford: Stanford University Press.

Dobbs, Jeanine. 1977. “Viciousness in the kitchen": Sylvia Plath's Domestic Poetry. Modern Language Studies 7: 11-25. [CrossRef]

Foucault, Michel. 1998. Different Spaces. In Essential Works of Foucault 1954-1984. Edited by James D. Faubion. New York: The New Press, vol. 2, pp. 175-85. Originally published as 1984. Des Espaces Autres. Architecture, Mouvement, Continuité 5: 46-49.

Friedan, Betty. 1983. The Feminine Mystique. New York: Dell. First published 1963.

Gilbert, Sandra M., and Susan Gubar. 2000. The Madwoman in the Attic. The Woman Writer and the Nineteenth-Century Literary Imagination. New Haven: Yale University Press. First published 1979.

Gill, Jo, ed. 2006. The Cambridge Companion to Sylvia Plath. Cambridge: Cambridge University Press.

Gill, Jo. 2008. The Cambridge Introduction to Sylvia Plath. New York: Cambridge University Press.

Gómez Reus, Teresa, and Terry Gifford, eds. 2013. Women in Transit through Literary Liminal Spaces. Basingstoke: Palgrave Macmillan.

Hinds, Lynn B., and Theodore Otto Windt Jr. 1991. The Cold War as Rhetoric. The Beginnings: 1945-1950. New York: Praeger.

Kroll, Judith. 2007. Chapters in a Mythology. The Poetry of Sylvia Plath. Stroud: Sutton.

Lacan, Jacques. 2006. The Mirror Stage as Formative of the I Function as Revealed in Psychoanalytic Experience. In Écrits. The First Complete Edition in English. Translated by Bruce Fink, Héloïse Fink, and Russell Grigg. New York and London: W.W. Norton \& Company, pp. 75-81. Originally published as 1966. Le Stade du miroir comme formateur de la fonction du Je. In Écrits. Paris: Seuil, pp. 93-100.

Lefebvre, Henri. 1991. The Production of Space. Oxford: Blackwell. Originally published as 1974. La production de l'espace. Paris: Éditions Anthropos.

Lindberg-Seyersted, Brita. 1990. Sylvia Plath's psychic landscapes. English Studies 71: 509-22. [CrossRef]

Martin, Deborah G., and Byron Miller. 2003. Space and Contentious Politics. Mobilization: An International Quarterly 8: 143-56. [CrossRef]

Massey, Doreen B. 1994. Space, Place, and Gender. Minneapolis: University of Minnesota Press.

May, Elaine T. 1988. Homeward Bound: American Families in the Cold War Era. New York: Basic Books.

McDowell, Linda. 1999. Gender, Identity, and Place: Understanding Feminist Geographies. Minneapolis: University of Minnesota Press. 
Medhurst, Martin J., and H. W. Brands, eds. 2000. Critical Reflections on the Cold War: Linking Rhetoric and History. College Station: Texas A\&M University Press.

Nadel, Alan. 1995. Containment Culture: American Narratives, Postmodernism and the Atomic Age. Durham: Duke University Press.

Nelson, Deborah. 2002. Pursuing Privacy in Cold War America. New York: Columbia University Press.

Nelson, Deborah. 2006. Plath, history and politics. In The Cambridge Companion to Sylvia Plath. Edited by Jo Gill. Cambridge: Cambridge University Press, pp. 21-35.

Peel, Robin. 2002. Writing Back: Sylvia Plath and Cold War Politics. Madison: Farleigh Dickinson University Press. Perloff, Marjorie. 1985. Icon of the Fifties. Parnassus 12-13: 282-85.

Piette, Adam. 2009. The Literary Cold War: 1945 to Vietnam. Edinburgh: Edinburgh University Press.

Plath, Sylvia. 2005. The Bell Jar. London: Faber and Faber. First published 1963.

Plath, Sylvia. 1981. Collected Poems. Edited by Ted Hughes. London: Faber and Faber.

Rose, Jacqueline. 1992. The Haunting of Sylvia Plath. Cambridge: Harvard University Press.

Rosenblatt, Jon. 1979. Sylvia Plath: The Poetry of Initiation. Chapel Hill: University of North Carolina Press.

Rotskoff, Lori. 2002. Love on the Rocks: Men, Women and Alcohol in Post-World War II America. Chapel Hill and London: University of North Carolina Press.

Shands, Kerstin W. 1999. Embracing Space: Spatial Metaphors in Feminist Discourse. London: Greenwood Press.

Smith, Susan J. 1999. The Cultural Politics of Difference. In Human Geography Today. Edited by Doreen Massey, John Allen and Philip Sarre. Cambridge: Polity Press, pp. 129-50.

Tally, Robert T., Jr. 2012. Spatiality. London: Routledge.

Tuan, Yi-Fu. 1990. Topophilia. A Study of Environmental Perceptions, Attitudes and Values. New York: Columbia University Press. First published 1974.

Turner, Victor. 1970. Betwixt and Between: The Liminal Period in Rites de Passage. In The Forest of Symbols. Aspects of Ndembu Ritual. Ithaca and London: Cornell University Press, pp. 93-111. First published 1967.

Van Dyne, Susan R. 1994. Revising Life: Sylvia Plath's Ariel Poems. Chapel Hill and London: The University of Carolina Press.

Van Gennep, Arnold. 1960. The Rites of Passage. Translated by Monika B. Vizedom, and Gabrielle L. Caffee. Oxford and New York: Routledge. Originally published as 1909. Les Rites de Passage. Paris: Émile Nourri.

Woolf, Virginia. 2015. A Room of One's Own and Three Guineas, 2nd ed. Edited by Anna Snaith. Oxford and New York: Oxford University Press. First published 1929. 